\title{
International Students' Perceptions and Experiences of British Drinking Cultures
}

\author{
Revised submission to Sociological Research Online December 2017
}

\begin{abstract}
While the increased scale and importance of international students to the UK Higher Education sector is now well established, little is known about the ways in which students from non-UK countries experience and interact with the heavy drinking culture that predominates on and near many British universities. Drawing on qualitative interviews, this article analyses the perceptions, attitudes and experiences of British drinking cultures held by international students studying on postgraduate courses at a UK university. Students report prior awareness of alcohol consumption being important to British culture and recount both positive and negative experiences of witnessing and, for many, participating in drinking alcohol. Students make ready comparisons with the drinking habits and attitudes of their own culture. Further still, many made a distinction between the public house, or 'pub', as a welcoming and friendly social space and bars and nightclubs where a far greater risk of exposure to violence and harassment was perceived. The article provides theoretical insights to support future and more wide-ranging research into mobile drinking cultures and also suggests practical implications to inform stakeholders with interests in the welfare of international students in the UK in relation to the provision of effective and proactive policies which address the impact of British drinking cultures on international student integration and wellbeing.
\end{abstract}

Keywords: Alcohol, Drinking Culture, Intercultural Interaction, International Students, Student Mobility

\section{Introduction}

A culture of excessive alcohol consumption and drunkenness is said to predominate at universities in the UK (Gill, 2002), the USA (Vander Ven, 2011) and beyond (Hebden et al., 2015), yet little is known of the perceptions and experiences of the large numbers of international students who come into contact with such drinking cultures. Activities centred on alcohol may exclude many international students who often come from cultures marked by moderation or abstinence (Humfrey, 1999) and may exacerbate the already well-documented lack of interaction between international and home students (Montgomery, 2010; Forestier, 2013). With 19\% of the 1,830,000 students attending UK universities in 2014-5 coming from other EU (5\%) and non-EU (14\%) countries, and with international students contributing $£ 10.8$ billion to the UK economy, supporting over 200,000 jobs through tuition fees, accommodation and off-campus expenditure (Universities UK, 2017), it is 
surprising that so few studies have sought to explore international students' experiences of UK drinking cultures. This article, therefore, explores cultures surrounding alcohol consumption in the United Kingdom as experienced and perceived by international postgraduate students studying at UK universities and suggests that mobile drinking cultures, where individuals traverse contexts with markedly different attitudes and expectations relating to alcohol consumption, give rise to interesting reflections on the nature of alcohol consumption as a socially and culturally embedded practice (Author A).

While there has been an increase in scholarly and pedagogical interest in international student mobility, this research has predominantly been concerned with the academic and sociocultural challenges and adjustment issues faced by students and the associated implications for universities and support services. While Verbik and Lasanowski (2007) identify social activities as a significant motivational factor for international student mobility, very little research attention has focused on the extracurricular leisure habits of international students and no research has specifically addressed their reactions to the prominent role played by alcohol consumption in UK university life and in wider British society. Addressing this gap in knowledge, the article draws on exploratory qualitative research with UK-based students of diverse national origins to outline and analyse the alcohol consumption patterns, preferences and practices of international students before and following their arrival in the UK and assesses the positive and negative social and cultural impacts of the UK's drinking cultures that they have experienced. The research seeks to provide theoretical insights to support future and more wide-ranging research and aims to inform a range of stakeholders with interests in the welfare of international students in the UK, especially in relation to the provision of more effective and proactive policies addressing international student integration and wellbeing.

\section{Putting Student Drinking Cultures in Context}

The growth in numbers of international students studying at UK universities in recent years has led to an increased need to understand the experiences of overseas students as they live, study and socialise during their time in the UK (Humfrey, 1999; Montgomery, 2010). Yet little is known about how international students experience and negotiate the cultures of alcohol consumption (and at times, heavy drinking) which have been shown to proliferate on and around UK university campuses (Gill, 2002). Indeed, there are ongoing concerns that many international students feel excluded by the centrality of drinking and drunkenness to the UK student experience (Forestier, 2013; Gil, 2014) and may be marginalized by the 'binge drinking' which dominates both academic and public debates about drinking in the UK (Plant and Plant, 2006). |Humfrey (1999: 89), for instance, notes that 'activities centred around alcohol will make attendance impossible for some [international] students and unacceptable to others' while Lewins (1990: 103) warns that 'a penchant for the pub or disco as 
the basis for their socialization' amongst British students may exacerbate the lack of integration between home and overseas students. As Montgomery (2010: 89) observes, the centrality of the pub and of drinking in British student life can be a significant 'psychological barrier' for international students' social interaction and integration. Further, a training guide produced by the UK Council for International Student Affairs expressed concerns for international students who 'don't like to be in a place or near people who are drinking alcohol' because this is either 'contrary to personal, cultural or religious values' or due to them being 'afraid of mixing with drunk people' (Bloxham et al., 2009: 41).

The National Union of Students (NUS), launching its Alcohol Impact partnerships, acknowledged that 'for the huge number of students who don't drink alcohol, campus life isn't as inclusive as we'd like it to be'. These tensions between the cultures of moderation and abstinence familiar to many international students and the hedonistic drinking practices and cultures which dominate some aspects of the student experience in the UK are addressed by various publications and resources offering advice and guidance to current or potential international students (e.g. Hyde, 2012). Notably, the British Council's official website (2017) for international students who are interested in studying in the UK explains that pubs have 'a long history and are an important part of UK culture' and that going to the pub is 'one of the most popular ways to spend an evening in the UK' and describes pubs as 'very welcoming, safe places' but warns of a 'minority' that 'can be rowdy'. A tension, therefore, emerges where drinking alcohol and visiting drinking venues is identified as an integral feature of British culture which may facilitate friendship and sociability, yet, at the same time, one which can be challenging for students of diverse nationalities to access.

Given the approach which sees the social role of alcohol as both complex and specific to particular cultural contexts predominant in anthropological and sociological understandings of drinking cultures (Douglas, 1987; Wilson, 2005: Author A), the case of international students' experiences of and within the drinking culture of the UK is apt for further investigation. For instance, both Järvinen and Room (2007) and Gordon et al. (2012) found that attitudes, perceptions and patterns of alcohol consumption vary by sociocultural context. In particularly, UK drinking culture has frequently been seen to contrast with the more sociable and less excessive drinking practices of continental Europe (Tierney, 2006). In spite of recent increases in the proportion of young adults reporting that they do not drink alcohol at all (ONS, 2015; Quine, 2016), the image of student drinking in the UK remains one primarily concerned with excess and typified by a hedonistic, though for many participants pleasurable, lack of control (Hubbard, 2013). Whilst such heavy drinking cultures exist amongst students in other countries (e.g. see Fjær and Tutenges, 2017), a popular perception is that this style of drinking is particularly indicative of the UK and US student experience. However, a review of evidence by Wicki et al. (2010) suggests that, across a number of studies of student drinking in 
various European contexts, students drink primarily for social reasons and tend to drink more heavily when living in the context of reduced responsibility that the student lifestyle often entails.

Yet, there have been only limited attempts to make more sustained cross-cultural comparisons of students' drinking habits and practices, and research into the experiences of students who either do not drink or drink only in moderation is rare (Romo, 2012). For instance, Chu et al. (2016) have compared German and Chinese students to find lower levels of drinking in the latter whilst recent work by Aresi et al. (2016) involving focus groups with Italian students found that alcohol and associated social activities and experiences were a notable feature of students' expectations of participating in overseas student exchange programmes (Aresi et al., 2016). The general lack of research is troubling. For instance, as Anand et al. (2015) have identified a negative correlation between spirituality and alcohol intake with religious faith being associated with abstinence and moderation, it can be assumed that the increasingly diverse student intake of UK universities, both in terms of international students and British students of ethnic or religious minority backgrounds, ought to precipitate an increasingly diverse range of student drinking practices that include alternatives more focused on moderation and abstinence (Hopkins, 2011). Further, whilst a link has also been made between distance from home and the freedom to drink alcohol, many international students link their fears of being subjected to abuse and victimisation with the drunkenness of others, particularly male strangers in public spaces (Author B).

In exploring these themes further, it is important understand how the physical, spatial and social context of alcohol consumption is important and diverse (Roberts et al., 2012; Jayne et al., 2016). While much student drinking takes place in halls of residence, off-campus mixed-occupancy houses and commercial drinking venues such as pubs, bars and clubs aimed at students (Kypri et al., 2010), contacts with non-student drinkers are, perhaps, increasingly exceptional. Thus, while the pub has been shown to play an important role in sustaining local communities through providing spaces of social interaction (Mount and Cabras, 2016), the growth of 'student-enclaves' consisting of exclusionary 'student-only' residential and leisure spaces (Smith and Hubbard, 2014) means that in some areas of British cities there is resentment amongst some local residents towards students with much of this tension focusing on noise and nuisance caused by student drinking (Sage et al., 2012). While the appeal of attracting large numbers of international students to university towns and cities can therefore be seen as part of the 'urban renaissance' with the economies of post-industrial cities reoriented towards retail, leisure and hospitality (Thomas and Bromley, 2000), this trend arguably gives rise to questions about inclusion and vulnerability that such debates tend to overlook. This is particularly worrying given the way in which gender, social class and ethnicity influence both the use and perception of urban leisure space (Scraton and Watson, 1998) and certain drinking spaces, in 
being dominated by white males (Spracklen et al., 2013), can deter female and ethnic minority drinkers.

As such, while the abiding image of night-time urban drinking is one of excess, hedonism and disorder (Jayne et al., 2006), the heavy drinking culture of the UK night-time economy is one from which ethnic and religious minorities can feel, and effectively be, excluded. While the British Council, and many city and university marketing teams, may invoke the image of the British pub as a safe and friendly leisure space in their bid to market studying in the UK as part of a wider experience of intercultural exchange, the suspicion remains that significant numbers of international students either do not desire or do not feel confident in accessing such leisure spaces. Following an outline of the methods used in conducting this research, the article will explore these issues with the aim of providing insights from which a better understanding of the lived experiences of international students can be derived.

\section{Methodology}

A qualitative approach was adopted in this study as it was felt to be the most suitable way to address a potentially sensitive research topic (see Figueroa-Domecq et al., 2015). In order to sensitise ourselves to the research topic and to assess its importance and relevance to international students, we ran a discussion group in April 2017 involving a total of eight students, from countries including South Korea (2), Greece (3), Malaysia (1) and China (2). This discussion helped to refine the research questions and to further the researchers' understanding of the topic before commencing the major data collection phase. This next stage consisted of in-depth one-to-one interviews, which allowed participants to express themselves freely in a private setting. As Rubin and Rubin (2012) note, the indepth interview permits the exploration of differing perspectives, experiences and opinions. A flexible approach was taken allowing participants to lead discussion; this is particularly important in an exploratory study on a topic on which relatively little is known (Pidd et al. 2014). Thus each interview proceeded differently, depending on the particular background and attitudes of the interviewee. It was important that the interview felt like a conversation, that participants felt relaxed, in order to obtain good quality data (Morris, 2015).

Interviews were conducted in English as the lingua franca of the participants and interviewer. Ten international students were interviewed over a two-week period in May 2017 at a university in Southern England. Purposive and convenience sampling was employed in order to select informationrich individuals (Jones et al., 2013). The participants had to be international (defined as non-British) students studying in England. Participants were from the following countries (gender indicated in brackets): Nigeria (M), America (F), Turkey (F), Italy (M), Poland (F), St. Vincent (M), Spain (F), 
Holland (M), Greece (F), and Germany (F). Participants were studying on a variety of academic programmes, mostly at postgraduate level. Ethical considerations were paramount. A participant information sheet and a consent letter were given to participants. All interviews were recorded with assurances of maintaining confidentiality and anonymity, meaning that pseudonyms are used throughout the article to refer to specific students. Finally, participants were assured of their right to withdraw from the project, including during the interview itself.

Thematic analysis was adopted to analyse the data. This involved the processes of familiarisation, coding and categorising (Braun and Clarke 2006). Firstly the interviews were transcribed, read separately by the authors to note initial ideas and emergent themes, before being re-read several times to refine coding themes. Subsequently codes were grouped to form discrete categories, or themes (Grbich, 2007), which are reflected in the structure of the findings sections. The themes generated during analysis are corroborated by the data collected from the discussion group, thus the data's trustworthiness is improved.

\section{'Oh, so they like drink to the extreme': International Students' Prior Perceptions of British Drinking}

When addressing their prior perceptions of British drinking culture, the focus group participants and the students interviewed expressed the belief that the British 'like to drink' (the exact words used by Greek, Polish, Vincentian and Dutch students), often to excess. For example, Mila, a female student from Germany, said that 'Of course it's not everybody, but I guess that's what their image in other cultures might be that if there is something to drink, they go for it and drink it'. Similarly, David, a male student from the Caribbean island St Vincent, reflected on his prior knowledge of British drinking culture by saying 'I knew they drank a lot, so I expected them to be drinking a lot and be doing lots of binge drinking and being drunk on the road'. David then elaborated on this by indicating that his knowledge had been informed by reading British blogs prior to coming to the UK where he 'saw English people getting drunk' and by following celebrities who are 'British', 'young' and 'drunk'. Interviewees therefore noted their prior exposure to the image of the young British binge drinker through cultural imagery circulating by word-of mouth and the media. Many were aware of the pejorative term 'binge drinking' (Plant and Plant, 2006) and, as such, arrived in the UK with preconceptions of heavy drinking being something British people are particularly prone to.

Prior perceptions, such as female Turkish student Seda's that 'I expected that everyone is into drinking and everyone is going to the pub', therefore framed anticipation pre-arrival in the UK. In several cases, this was specifically invoked as something intimidating or fearful. For example, female Spanish student Inés recalled that: 
I had a very scary perception of the drinking habit of British students. I always thought, 'Oh, so they like drink to the extreme, like when they like black out and they cannot remember the night and they think that's normal'. It wasn't very positive. I knew of course, it's a bit like people were exaggerating, like you do with stereotypes, but I was still a bit cautious about it.

In comments such as Inés's, alcohol consumption is firmly located as something cultural and collective rather than a simple matter of individual preference or, as would be in line with much social policy discourse (Hackley et al., 2008), individual deviance.

\section{'As they got too drunk I'm just like, 'Nope, I'm out': Experiences of British Drinking Culture Following Arrival}

While many of the students acknowledged that their prior expectations were influenced by media representations of British drinking culture that were stereotypical or exaggerated, prior expectations appeared to remain, and be reinforced, after arrival in the UK. Students tended to describe heavy drinking as something specifically cultural, as part of a wider British attitude and 'way of life'. Interviewees therefore appeared to moderate their opinions with frequent reference to their awareness that such hedonistic behaviour was a product of the social and cultural context. Matteo, a male Italian student, exemplifies this in saying:

I kind of noticed that the amount of alcohol that they're able to [consume] is, like, really high, very high, like. It's not a bad culture, it's just people yeah drink a lot, they should just maybe control more themselves. It's cool, like I drink too, it's cool to drink, it is alright, there is nothing wrong with it as long as you control yourself, that the only thing because you can get in, you know, danger and hurt other people, which is not good.

Similarly ambivalence is expressed by female American student Emily, who observed that the 'chronic excessive drinking' of UK undergraduates was 'a social thing':

I just was astonished and I'm still astonished at the amount of drinking for undergraduates. I don't know, I'm not impressed by people drinking to get drunk. Like I understand it's a social thing, but like drinking to get drunk it's just for me, personally I just, I've never understood it.

Notably, Emily went on to explain 'I would hang out with [my course mates] because I wanted to hang out with them but then as soon as they got too drunk I'm just like, 'Nope, I'm out, like I'm not staying around here, this is ridiculous!'. Significantly, Emily's comments imply that rather than a 
strict binary between inclusion and exclusion, she is put in a position to negotiate her participation where her initial willingness to socialise with fellow students is curtailed at a point where their drinking becomes, by her definition, excessive.

This ambivalence about British drinking cultures, that became a striking feature of many interviews, typically acknowledging that some drinking was expected and understood as enjoyable, but that too many British students, in the words of Alicja, a female student from Poland, 'don't know when to stop'. While moderation, as Yeomans (2013) rightly explains, is a contested concept, interviewees could all make specific reference to examples of British students 'going too far'. A common framing made in the interviews was therefore one of compulsion where, for British students, a culture of heavy drinking was too strong for most to resist. This was evident in Vincentian student David's account of observing instances of peer pressure where his fellow students coerced each other into continued heavy drinking:

It's a lot of peer pressure I see in the drinking, like you would see one guy drinking and if he is drinking too slow you would see his friends start cheering him on, they start singing to him and encouraging him to drink more, so I've seen that. Peer pressure is very high here. I even had some friends here that weren't drinkers but once they came out, there was no option, they HAD to drink, so be prepared to drink something or stay home.

While moral judgements about badly behaved British students pervaded interviewees' accounts, so too did a willingness to view their own increased knowledge of British drinking as part of their enhanced understanding of British culture more generally. This frequently involved coming to terms with the apparent dissonance from pre-conceptions of 'polite' English culture. For example, female Greek student Katerina observed that:

When they start drinking, it's like all the nice things I can say about the English culture - how they're gentleman, they're kind and everything - when they start drinking, it's like those rules don't apply anymore, like manners are out the window.

These and other comments therefore showed how international students gained new awareness of British drinking culture, specifically, and of British people, attitudes and what many clearly viewed as eccentricities, more generally. For instance, several interviewees spoke about realising, and being surprised by, the predominance of 'pre-loading' among British students where students would drink off-trade purchased alcohol at home prior to visiting commercial drinking venues such as pubs, bars and clubs (See Barton and Husk, 2014). Polish student Alicja described this, somewhat comically, as a practice where 'they go to a pre-pre-pre-drinking party and then they go to a pre-pre-drinking party 
to go to the pre-drinking party to go to the drinking party, and like that's insane to me, like that's so much alcohol'. Likewise, Inés stated that she 'did not know pre-drinks was a thing' before arriving in the UK from Spain. In this way, many of the students appeared to associate learning about British drinking culture, albeit at times from a distance, as part of their wider experience of the international student sojourn.

\section{'Back in my country...we frown at people drinking without limits': Contrasting Host and Home Drinking Cultures}

It was perhaps inevitable that participants compared British drinking habits and attitudes to those of their own country. For example, David noted that 'back home, drinking, it's just very laid back and it's just something that comes like second nature, just take a drink and be calm. That's basically the big difference'. Further still, such contrasts between host and home drinking cultures occupied a significant proportion of the interviews and were evidently a means for participants to make sense of their personal reaction to some of the hedonistic excesses they had witnessed. Victor explained how:

Back in my country Nigeria, we frown at people drinking without limits, you understand. People that drink to the excess that they start to behave badly in public are always given a bad label and no one would want to do to do that. In Nigeria, you get rebuke straight on, so coming here and people was just minding their business like it's nothing, so yeah I find that really repulsive and shocking and it's kind of going along the narrative of Britain being a permissive society where anything goes.

Notably, it is not suggested that Nigerians do not drink, or that there are no risky or excessive drinking behaviours in Nigeria. Rather, Victor appears to invoke a strong sense of social regulation and functional propriety in his 'home' culture. Similar lines of distinction were drawn by Katerina, who said that:

Here, it's like, 'oh my god, I can't remember my whole weekend!' which is, yeah you wouldn't brag about that in Greece. If you throw up, it's extremely embarrassing especially for a woman, it's very not attractive. So it's a completely different mind-set of what you think is cool and what is not. For us, drink is always there on the table when we go out and stuff, but it's not the main goal. The goal would be to have fun, to meet people, which includes alcohol but we won't say, 'oh let's go out, get drunk'. That is not acceptable, it's not cool really. 
Victor and Katerina are notably disparaging in these comments, with 'behaving badly in public' and getting so drunk that 'you throw up' being derided as 'really repulsive and shocking' and 'extremely embarrassing'. Such comments demonstrate the way that alcohol consumption practices are learnt as part of embodying a particular habitus (Brierley-Jones et al., 2014) meaning that responses to the 'wrong' sort of drinking behaviour in others are characteristically pitched at an emotional and moral level and appear to be rooted in habituated and embodied understandings of proper or improper drinking comportment.

In several interviews, a discourse of gendered respectability, which weighs particularly heavily on female drinkers (Griffin et al., 2013; Hutton et al., 2016), was evident through references to the 'shameful behaviour' of some British women, depicted as highly visible with 'tiny skirts' and 'lots of flesh on display'. For example, German student Mila described her observation of how 'they even get so drunk in the winter that they don't feel that they're cold anymore because they all running around in their short little dresses'.

Yet, some other participants were more equananimous about British drinking habits and showed willingness to accept both relative similarities with their own culture's attitudes to alcohol and, in some cases, to highlight positive opinions of British drinking. Thus, Alicja, conceded that 'I think we drink a lot in Poland as well', whilst Seda reflected that 'I think Turkish people are angrier when they are drunk; yeah they can be scarier than British people because British people are generally calm'. Learning why, when and how people drink in the UK, and contrasting this to their own country, can therefore be seen as part of a wider intercultural awareness that students developed by studying in the UK.

'I went straight away when I came to England, to have time in a pub': The Pub as Site of (Inter)Cultural Sociability

A consistent theme in all interviews was the public house, 'the pub', as distinctly British and, as such, something worth experiencing even for those students with the least motivation to consume alcohol. Indeed, many participants were alerted to the importance of the pub as a meeting place before their arrival through its portrayal in media such as films and TV programmes, and were consequently determined to visit a pub, as an important facet of British culture. Here, the international circulation of media images and texts appears to have helped disseminate a relatively consistent and widely known image of British drinking culture. The emphasis placed on the British pub as an iconic aspect of British culture by for example, the British Council, noted earlier, does appear to be reflected in real perceptions held by many students. For instance, Katerina said that: 
It seem to me like very traditional place where people hang out. Even if you have never been in a pub, from the movies you would know, that's a pub. I went straight away when I came, to England to have time in a pub. I wanted to see what the big deal is, why it's so important and why it lasted all these centuries and why it's so important for the British people.

This understanding of the pub as an iconic cultural institution was repeated by both Alicja, who saw the English pub as something 'which is really familiar' to her from watching 'English movies [where] they sit in pubs and drink', and Inés, who recalled that on arrival she 'really wanted to go to a pub and see like what it's was all about, I wanted to eat there, I wanted to try real British beer'. Seda described her expectation of 'a big, big, big room with lots of chairs and with cheerful people' based on film and TV representations of British life and recalled an article in which 'an author mentioned that a pub in England is a common room of a house, everyone is just meeting in the pub'. The interviewees all appeared to agree that alcohol consumption could offer a sense of sociability and belonging (Griffin et al, 2009). Notably, the pub was understood, somewhat optimistically, to be an egalitarian and welcoming space, akin to Oldenburg's (2001) concept of the 'third place'. For example, Matteo described how:

I just go to the pub, just go for drinks, that the most common way to hang with new people, meeting new people, sharing some beers. I'm offering you, you offering me, that's the way it works. I just usually go there with my friends and we just enjoy our drinks and we chat [...] and it happens that maybe you bump into somebody else, maybe you smoking a cigarette outside and you just get into chat, and ah you know you mingle and you meet other people.

Further, upon observation of the important place occupied by the pub in British culture, several participants spoke of learning to integrate its use for socialising into their own life. Victor referred to a change in his drinking habits and spoke of demonstrating his liking for the pub to 'some of my friends, African friends, Caribbean friends, and friends from other parts of the world'. Similarly, Katerina spoke at length of having learned to enjoy the atmosphere of the pub but added that this was specifically 'the calm hours where you can speak with your friends, play games' and that she avoided 'going very late [to the] pub' due to the change in atmosphere.

The interviews indicate that many international students do indeed value the pub as a space of social interaction both with fellow students and, in some cases, with others including non-student 'locals' beyond the confines of campus and purpose-built student accommodation 'enclaves' (Author C; Smith and Hubbard, 2014). For example, Dutch student Jasper said that: 
If you live in halls here it's mostly international students, at least for the masters, but like in a pub it's pretty much all English people so that's definitely a good place to meet more English people. It's kind of like a meeting place, a place that friends meet up to watch the game or have a drink together. I think pretty welcome, like I think the atmosphere is really nice and the people are generally really nice here so I do feel like yeah, it's a good experience. It's a really fun way to get introduced to a lot of English people.

However, these accounts, that saw students such as Alicja and Katerina describing the pub as 'really welcoming' and 'very friendly' respectively, were not repeated once conversation turned to bars, nightclubs and the night time economy more generally. Interviewees reported experiencing such spaces as threatening and spoke of their dislike of the sense of risk and danger that heavy drinking and aggressive behaviour gave rise to. Seda, for example, reported that:

Once when we were trying to go into a night club there was a really, really big fight, just two young boys, I think they were about 19 or 20, they were really, really young, they were teenagers and they were fighting for no reason and the security guy tried separating them but he couldn't do that, he just called the police. We were kind of scared.

Similarly, David described disliking the city at night because:

[British people] get rowdy, here has probably a big fighting culture, when they drink they you know is always some scuffle or some argument happening, it's never anything too violent just mostly fist fights.

Alicja also reported violence and, like others, associated it with very young drinkers who were unable to control themselves when drinking:

Most of my experiences in a pub were really good, I mean you just come there to drink and I've never met anyone in the pub being aggressive. But clubs are much different...I had one situation when I went to the club with my friends, we were just dancing on the dance floor and then a young guy, he just punched my boyfriend from the back and there were some girls and they were trying to fight with us and we didn't do anything to them. I said to the security 'why, why you haven't done anything when those people just interrupt us?' and they didn't care so I was really put off and I don't really like to go to the clubs. I prefer pubs much more because you can just spend nice times with your friends rather than go to the club and have situation like that. 
This potential for violence at night is noted by Author B, who documented a high degree of racism against international students in the UK, which led to their participants adopting self-protective strategies, including avoiding going out at night. Strikingly, we see how both the perception and actual experience of risks and danger present in the night time economy led both Inés and Katerina, respectively, to give accounts of how they learnt to avoid certain spaces or to strategically modify their mobility through the local urban space by saying:

There is a time I think, like, around 1 or 2 am when things can get really ugly because people start fighting, like I think it's very easy to fight. There is a pub down my street, I've seen an ambulance in front of the pub more often than I need to, like that's why I don't go to that one.

I have experience before where people would follow us from the pub and that is very very scary. It was a couple of times we left the pub with a group of friends, us girls and we would have people following us and we would have to take a detour because we didn't want to go home and we had to pretend we talk on the phone to the police for them to stop. How men behave, it can be dangerous [...] I'm starting to learn what to avoid, which hours, not to go alone, when we go out to go back home in groups just to take care of ourselves.

These concerns relate to what Thomas and Bromley (2000: 1245) have referred to as a 'spatial expression of anxiety' whereby parts of the city centre at night are 'widely perceived as a threatening environment'. They also resonate with recent work by Nicholls (2017) which shows many young women engaging in active management of their gendered and sexualised visibility as they negotiate their presence in the night time economy.

\section{Alcohol, Drinking Cultures and International Student Mobility}

The research findings show that interviewees have all, in various ways, engaged with UK drinking culture and that, further still, the heavy drinking associated with the UK student experience prompted them to reflect on their own relationship with alcohol and the spaces where alcohol is consumed. A common theme of the interviews has been one of prior expectation, initial shock or amazement, then growing familiarity and selective or ambivalent acceptance. Whilst interviewees participated in British drinking culture to varying degrees, with Matteo and Victor both reporting regularly drinking in pubs with both student and non-student friends, all interviewees recounted how they had necessarily and willingly acquired a more nuanced understanding of British drinking culture, specifically, and British culture, generally, during their time living and studying in Britain. While many spoke approvingly of some aspects of British drinking culture, all invariably remained aligned to the drinking culture prevalent in their own country. International students who sought out or 
otherwise participated in drinking opportunities whilst studying in the UK appeared to frame this as part of a more general desire to engage with, experience and learn about the culture of their 'host' country. Drinking alcohol specifically for the pleasure of intoxication and enjoying the open and sociable environment offered by pubs was spoken of with a measure of pride akin to evidence of cultural immersion and learning to successfully negotiate the cultural landscape of their new context. This involved, particularly for female interviewees, awareness of dangers associated with violence and aggression which were seen as being particularly prevalent in the night time economy and in the 'wrong sort' of drinking locations.

A notable shortcoming of the now extensive literature on the cultural practices of alcohol consumption is the assumption of congruity where drinking is seen as specific to its social and cultural context. This assumption of congruity, that one 'learns' to drink in a manner fitting to one's context, largely overlooks those who are mobile in their movement between markedly different drinking cultures. Understandings of the way in which drinking cultures are learnt in context but become transportable, and perhaps adaptable, with the mobilities that increasingly characterise life in contemporary globalised societies are rare and, perhaps, have been limited to studies of tourist drinking (Author D; Tutenges, 2012) and rare examples of in-depth empirical research into alcohol consumption habits within a migrant / diaspora community (for example, Joseph, 2012).

As this research demonstrates, international students studying in the UK are spatially and culturally mobile in being temporarily located in a cultural context other than that of their socialisation. Thus, as the recent study by Aresi et al. (2016) appears to indicate, the student mobility which has become an increasingly prominent feature of the higher education sector both in the UK and globally, is perhaps as likely to involve intercultural experiences and exchanges in the pub, bar, or at parties in halls of residence as they are in the classroom. The suggestion of the article is, therefore, that drinking cultures are mobile when drinkers are and that international students carry with them the drinking preferences, habits and practices of their 'home' habitus which, to varying degrees, may conflict with and adapt to those of the 'host' drinking culture. Mobility evidently provides these individuals with opportunities to encounter drinking cultures different from their own and, in the frequent contrasts made with their own cultural context, reflect on their own relationship with alcohol, drunkenness and excess.

\section{Conclusion}

This paper has explored the perceptions and experiences of British drinking cultures held by a diverse range of international postgraduate students studying at a university in Southern England. The spatial and social contexts of how, where and when international students have encountered the British 'in 
drink' have emerged as interesting and important considerations in their experiences of living in the UK. These experiences elicited surprise and concern among some participants. Contrasts were made with student drinking practices and social norms surrounding alcohol consumption 'back home' with comparisons drawn that were largely unfavourable to the UK. This research also has practice and policy implications for university administrators, student unions and stakeholders with interests in public health and student welfare and well-being. With $27 \%$ of 16 to 24 year olds now teetotal (ONS, 2015), the findings can also develop greater understanding of the social needs of non-drinking students at UK universities. Recent alcohol policy has positioned young people as 'problem drinkers' and largely ignored the positive connotations of drinking as an accessory to social fulfilment (Hackley et al, 2008). Here, alcohol consumption occasions have offered many interviewees opportunities for intercultural sociability.

We might infer a degree of selectivity in that students interviewed have chosen to study in the UK. As well as a perception that the UK is now less welcoming (Shaw, 2014), those who chose other countries as destinations for their studies may have actively avoided UK universities given the widespread pre-arrival perception of British heavy drinking. Likewise, given the cost of study in the UK, in spite of coming from diverse cultural backgrounds, the attitudes to alcohol analysed here could therefore be specific to the social class and cultural habitus from which international students tend to come from. Further, the research was conducted in a small, single university city. Future research may consider other types of campus setting such as universities in larger metropolitan areas or universities located in regional or provincial settings, which may provide more or fewer alternatives to alcoholbased social activities and a more or less culturally diverse social milieu respectively. Such research could expand on anecdotal evidence, based on personal experience of the authors, that many international students perceive campus universities as 'safer', and therefore more appealing, than universities in metropolitan settings.

Further research is also needed to explore the perceptions held and experiences of younger international students during their sojourns in the UK, with pre-university students at English language schools, some of whom are below the legal age to purchase alcohol being a particular concern in some university town and city settings. Notably, there is scope for research with a more longitudinal framing than the present study allowed to 'follow' international students and see if changes to drinking practice are taken 'home'. The research also indicates the scope for research which explores mobile drinking cultures, and associated experiences of British drinking culture, that are presented by other categories of short-term and long-term visitors and sojourners to the UK. This may include for example, international business travellers and temporary workers, tourists on organised, packaged group visits and longer established resident (diaspora) communities. 


\section{Bibliography}

Author Citation A (2015).

Author Citation B (2013).

Author Citation C (2017).

Author Citation D (2011).

Anand, V., Jones, J., \& Gill, P. S. (2015). The relationship between spirituality, health and life satisfaction of undergraduate students in the UK: An online questionnaire study. Journal of religion and health, 54(1), 160-172.

Aresi, G., Fattori, F., Pozzi, M., \& Moore, S. C. (2016). I am going to make the most out of it! Italian university Credit Mobility Students' social representations of alcohol use during study abroad experiences. Journal of health psychology. September, 1-10

Barton, A., \& Husk, K. (2014). "I don't really like the pub [...]”: reflections on young people and preloading alcohol. Drugs and Alcohol Today, 14(2), 58-66.

Beccaria, F. and Sande, A. (2003) Drinking Games and Rite of Life Projects: A social comparison of the young people's use of alcohol during the rite of passage to adulthood in Italy and Norway, Young, 11(2): 99-119.

Bloxham, J., Eade, K., Harrison, N. and Peacock, N. (2009) Discussing difference, discovering similarities: A toolkit of learning activities to improve cross-cultural exchange between students of different cultural backgrounds. Project Report. UKCISA. Available from: http://eprints.uwe.ac.uk/16262

Braun, V. and Clarke, V. (2006). Using thematic analysis in psychology. Qualitative research in psychology, 3(2), 77-101.

Brierley-Jones, L., Ling, J., McCabe, K.E., Wilson, G.B., Crosland, A., Kaner, E.F. and Haighton, C.A., 2014. Habitus of home and traditional drinking: a qualitative analysis of reported middle-class alcohol use. Sociology of health \& illness, 36(7), pp.1054-1076. 
Chu, J. J., Jahn, H. J., Khan, M. H., \& Kraemer, A. (2016). Alcohol consumption among university students: a Sino-German comparison demonstrates a much lower consumption of alcohol in Chinese students. Journal of Health, Population and Nutrition, 35(1), 25.

Douglas, M. (1987), Constructive drinking: Perspectives on drinking from anthropology. Cambridge: Cambridge University Press.

Figueroa-Domecq, C., Pritchard, A., Segovia-Pérez, M., Morgan, N., and Villacé-Molinero, T. (2015). Tourism gender research: A critical accounting. Annals of Tourism Research, 52, 87-103.

Fjær, E. G., \& Tutenges, S. (2017). Departies: conceptualizing extended youth parties. Journal of Youth Studies, 20(2), 200-215.

Forestier, K. (2013). 'Insight: Binge drinking on UK campuses alienates foreign students', South China Morning Post. 7 October 2013.

Gil, N. (2014). 'Chinese students think British boys are gentlemen, but when they get drunk they go crazy'. The Guardian Online. 20 October 2014. Accessible: https://www.theguardian.com/education/2014/oct/20/-sp-meet-a-student-from-china

Gill, J. S. (2002). Reported levels of alcohol consumption and binge drinking within the UK undergraduate student population over the last 25 years. Alcohol and Alcoholism, 37(2), 109-120.

Gordon, R., Heim, D., \& MacAskill, S. (2012). Rethinking drinking cultures: A review of drinking cultures and a reconstructed dimensional approach. Public health, 126(1), 3-11.

Grbich, C. (2007). Qualitative data analysis: An introduction. Thousand Oaks, Sage Publications.

Griffin, C., Bengry-Howell, A., Hackley, C., Mistral, W. and Szmigin, I., 2009. The allure of belonging: Young people's drinking practices and collective identification. Identity in the 21st century: New trends in new times, pp.213-230.

Griffin, C., Szmigin, I., Bengry-Howell, A., Hackley, C. and Mistral, W., 2013. Inhabiting the contradictions: Hypersexual femininity and the culture of intoxication among young women in the UK. Feminism \& Psychology, 23(2), pp.184-206. 
Hackley, C., Bengry-Howell, A., Griffin, C., Mistral, W. and Szmigin, I., 2008. The discursive constitution of the UK alcohol problem in Safe, Sensible, Social: A discussion of policy implications. Drugs: education, prevention and policy, 15(sup1), pp.61-74.

Hackley, C., Bengry-Howell, A., Griffin, C., Mistral, W., Szmigin, I. and Hackley, R. (2013) Young Adults and 'Binge' Drinking: A Bakhtinian analysis, Journal of Marketing Management, 29(7): 933949.

Hebden, R., Lyons, A. C., Goodwin, I., \& McCreanor, T. (2015). "When You Add Alcohol, It Gets That Much Better" University Students, Alcohol Consumption, and Online Drinking Cultures. Journal of Drug Issues, 45(2), 214-226.

HESA. (2017). 'Statistical First Release SFR242'. Higher Education Statistics Agency: Cheltenham, UK.

Hopkins, P. (2011). Towards critical geographies of the university campus: understanding the contested experiences of Muslim students. Transactions of the Institute of British Geographers, 36(1), 157-169.

Hubbard, P. (2013). Carnage! Coming to a town near you? Nightlife, uncivilised behaviour and the carnivalesque body. Leisure Studies, 32(3), 265-282.

Humfrey, C. (1999) Managing International Students. Buckingham: Open University Press.

Hutton, F., Griffin, C., Lyons, A., Niland, P. and McCreanor, T., 2016. "Tragic girls" and "crack whores": Alcohol, femininity and Facebook. Feminism \& Psychology, 26(1), pp.73-93.

Hyde, M. (2012). The international student's guide to UK education: unlocking university life and culture. London: Routledge.

Järvinen, M. and Room, R. (2007), Youth Drinking Cultures: European experiences, London: Ashgate.

Jayne, M., Holloway, S. and Valentine, G. (2006) 'Drunk and Disorderly: Alcohol, urban life and public space', Progress in Human Geography, 30(4): 451-468. 
Jayne, M., Valentine, G. and Holloway, A. (2016). 'Consumption and Context' in Handbook on Drug and Alcohol Studies: Social science perspectives, Koling, T., Thom, B. and Hunt, G. (eds). London: SAGE.

Joseph, J. (2012) Around the boundary: Alcohol and older Caribbean-Canadian men, Leisure Studies, 31(2): 147-163.

Kypri, K., Paschall, M. J., Langley, J. D., Baxter, J., \& Bourdeau, B. (2010). The role of drinking locations in university student drinking: findings from a national web-based survey. Drug and alcohol dependence, 111(1), 38-43.

Lewins, H. (1990). Living needs. The learning experiences of overseas students, 82-106.

Montgomery, C. (2010) Understanding the International Student Experience. Basingstoke: Palgrave Macmillan.

Morris, A. (2015). A practical introduction to in-depth interviewing. Thousand Oaks, Sage Publications.

Mount, M., \& Cabras, I. (2016). Community cohesion and village pubs in northern England: An econometric study. Regional Studies, 50(7), 1203-1216.

Nicholls, E. (2016). 'What on earth is she drinking? 'Doing Femininity through Drink Choice on the Girls' Night Out. Journal of International Women's Studies, 17(2), 77.

Nicholls, E. (2017). 'Dulling it down a bit': managing visibility, sexualities and risk in the Night Time Economy in Newcastle, UK. Gender, Place \& Culture, 24(2), 260-273.

Oldenburg, R. (Ed.). (2001). Celebrating the Third Place: Inspiring stories about the great good places at the heart of our communities. Da Capo Press.

ONS. (2015). Compendium: Adult Drinking Habits in Great Britain, 2013. London: Office of National Statistics.

Pidd, K., Roche, A. and Kostadinov, V. (2014). Trainee chefs' experiences of alcohol, tobacco and drug use. Journal of Hospitality and Tourism Management. 21, 108-115. 
Plant, M. and Plant, M. (2006) Binge Britain: Alcohol and the national response. Oxford: Oxford University Press.

Quine, Q. (2016). 'Generation Abstemious: More and more young people are shunning alcohol', The Independent, 15 January 2016.

Roberts, K., Townsend, T., Pappalepare, I., Elridge, A. and Mulyawan, B. (2012), Local Variations in Youth Drinking Cultures, Joseph Rowntree Foundation.

Romo, L.K. (2012), “Above the Influence': How college students communicate about the healthy deviance of alcohol abstinence', Health Communication, 27(7): 672-681.

Rubin, H.J., and Rubin, I.S. (2011). Qualitative interviewing: The art of hearing data. Thousand Oaks, Sage Publications.

Sage, J., Smith, D., \& Hubbard, P. (2012). The diverse geographies of studentification: Living alongside people not like us. Housing Studies, 27(8), 1057-1078.

Scraton, S., \& Watson, B. (1998). Gendered cities: women and public leisure space in the 'postmodern city'. Leisure studies, 17(2), 123-137.

Shaw, C. (2014). Fewer international science students come to 'unwelcoming' UK. The Guardian, 11 April 2014. Accessible: https://www.theguardian.com/higher-educationnetwork/2014/apr/11/international-science-students-shun-uk

Smith, D. P., \& Hubbard, P. (2014). The segregation of educated youth and dynamic geographies of studentification. Area, 46(1), 92-100.

Spracklen, K., Laurencic, J., \& Kenyon, A. (2013). 'Mine’s a Pint of Bitter': Performativity, gender, class and representations of authenticity in real-ale tourism. Tourist Studies, 13(3), 304-321.

Thomas, C. J., \& Bromley, R. D. (2000). City-centre revitalisation: problems of fragmentation and fear in the evening and night-time city. Urban studies, 37(8), 1403-1429.

Tierney, J. (2006), “We want to be more European': the 2003 Licensing Act and Britain's night-time economy', Social Policy and Society, 5(4): 453-460. 
Tutenges, S. (2012). Nightlife tourism: A mixed methods study of young tourists at an international nightlife resort. Tourist Studies, 12(2), 131-150.

Universities UK. (2017) Briefing: The economic impact of international students. London: Universities UK.

Vander Ven, T. (2011). Getting wasted: Why college students drink too much and party so hard. NYU Press.

Verbik, L., \& Lasanowski, V. (2007). International student mobility: Patterns and trends. World Education News and Reviews, 20(10), 1-16.

Wicki, M., Kuntsche, E., \& Gmel, G. (2010). Drinking at European universities? A review of students' alcohol use. Addictive behaviors, 35(11), 913-924.

Wilson, T. (2005) Drinking Cultures. New York: Berg.

Yeomans, H. (2013). Blurred visions: experts, evidence and the promotion of moderate drinking. The Sociological Review, 61(S2), 58-78. 